\title{
Sociocultural transitions and developmental impacts in the digital economy of impact sourcing
}

\begin{abstract}
Impact Sourcing (ImS) is the practice of bringing digitally-enabled outsourcing jobs to underprivileged communities. While such jobs are attractive and improve life chances, situated ImS employees face the difficult task of transitioning from their traditional communities to the relatively modern ImS workplace. These transition experiences expose them to a variety of work-life challenges, and at the same time serve as occasions for development. This paper draws on an inductive qualitative study of an up and coming Indian ImS company and explores how ImS employees experience sociocultural transitions and realize developmental impacts. The findings suggest that compartmentalization and integration strategies help ImS employees manage boundaries arising from the contrasting cultural expectations of the community and the workplace. ImS employees respond to sociocultural transition challenges in the workplace through a series of cognitive adjustments, which involves the creation of fictive kinships, job crafting and experimenting with provisional selves. Furthermore, the analysis shows how intense engagement with sociocultural transitions can lead to the development of crucial individual and collective capabilities. In closing, a model of capability development of ImS employees is outlined and the implications for ImS companies are discussed.
\end{abstract}

Key words: Digitally-enabled jobs, Impact sourcing, Sociocultural transitions, Development, India. 


\section{INTRODUCTION}

Impact sourcing (ImS) is the practice of bringing digitally-enabled outsourcing jobs to underprivileged communities ${ }^{1}$ (Carmel et al., 2013; Heeks, 2013; Sandeep \& Ravishankar, 2015). A social mission to positively impact, i.e. to improve the social and material conditions of underprivileged communities, characterizes companies engaged in this practice (Madon \& Sharanappa, 2013; Heeks, 2013). For ImS employees, transitioning from their traditional communities to the relatively modern ImS workplace can be a daunting experience. Inherited values, belief systems and practices often openly contradict the culture of ImS workplaces. Moreover, working with unfamiliar digital technologies entails a steep learning curve. Consequently, ImS employees experience cognitive and psychological challenges as they learn to balance new beliefs and values with the old, and develop new practices and skills. Previous research about transitions concur that workplaces place intense cognitive demands on "newcomers" (Van Maanen \& Schien, 1979; Jones, 1986; Raghuram, 2013), given that they may not yet possess the relevant resources and skills for effective performance (Molinksy, 2013). Moreover, transitions (both social and cultural) imply confronting numerous challenges not only within the workplace, but also outside, in the broader social community (Vasavi \& Upadhya, 2006; Raghuram, 2013).

Zittoun et al. (2003:417) notes that transitions are processes of elaboration following a rupture in the "taken-for-granted" and the emergence of unexpected situations. For ImS employees, such ruptures occur when they encounter contrarian worldviews and new information and communication technologies (ICTs) in the workplace. They also occur in the employees' relationship with their local communities as they begin to experience the ImS work environment. To successfully navigate these ruptures and re-establish control over their professional and personal lives, ImS employees devise a variety of strategies. This process also helps them develop new skills, construct new meanings, unlearn old habits and reach a new stability. Transitions, thus, can be viewed as "occasions for development" (Zittoun et al., 2003) where individuals reinvent aspects of their selves, making adjustments to

\footnotetext{
1 In the ImS context, underprivileged communities is a broad notion and includes those living on less than US $\$ 2.5$ a day (Heeks, 2013), disabled communities, young people in economically backward rural areas, low-income ethnic minorities and rural women.
} 
their personal and professional lives. However, these transitions are rarely one-off episodes of adjustments. Indeed, sequences of rupturing and strategic responses occur regularly, and in this sense transitioning is an on-going accomplishment that begins when employees make their entry into the organization and continues till the time of their exit (Van Maanen \& Schien, 1979).

The cost of "unsuccessful" transitions is high for both ImS employees and ImS companies. As the broader management research has demonstrated, individuals failing to transition may face sanctions in the workplace (Molinsky, 2013) and even lose their jobs (Liu et al., 2015). Alongside gaining technical proficiency and becoming productive within a short span of time, employees also need to fit-in and pick up "context-appropriate" behavior, carefully calibrating their actions in both work and non-work contexts (Raghuram, 2013). Equally, for organizations, a motivated, skilled and engaged workforce is central to competitiveness and productivity (Van Maanen \& Schein, 1979; Lu et al., 2014). ImS companies share their employees' anxiety to succeed in the new workplace especially because providing employment and achieving developmental impacts is a core organizational mission. While a small number of studies have started to highlight the potential impact of ImS on individuals and local communities (for e.g., Lacity et al., 2012; Madon \& Sharanappa, 2013; William Davidson Institute, 2013), there is scant research on how ImS employees manage sociocultural transitions and realize developmental impacts. In this paper, drawing on an inductive qualitative study of ImpactHub, an ImS company based in the northern part of India, we address two research questions: (1) How do ImS employees manage sociocultural transitions in the workplace and in the community? and (2) What are the developmental impacts realized in the process? To answer the first question, we draw on transitions-related concepts in the outsourcing, identity, and organizational socialization literatures. This body of work is particularly relevant since it illustrates individuals' management of sociocultural transitions across workhome boundaries (Raghuram, 2013) and explains how they form social networks to overcome anxieties in the work environment (Upadhya \& Vasavi, 2006; D'Mello \& Eriksen, 2010; Cooper-Thomas et al., 2011). It also explores how employees engage in cognitive reframing of difficult jobs (Wrzesniewski \& Dutton, 2001; Berg et al., 2010; Matarelli \& Tagliaventi, 2012) and build confident professional selves (Ibarra, 
1999). To answer the second question, we draw on concepts from the developmental studies literature (e.g. Sen, 1999; Comim \& Carey, 2001; Nussbaum, 2011) as well as on preliminary analyses undertaken in recent ImS research (e.g., Madon \& Sharanappa, 2013; Malik et al., 2013).

\section{SOCIOCULTURAL TRANSITIONS}

'We understand ... 'transition' not as a moment of change but as the experience of changing, of living the discontinuities between the different contexts ... Transitions arise from the individual's need to live and participate in different contexts, to face different challenges, to take profit from the advantages of the new situation arising from the changes. Transitions include the process of adapting to new sociocultural experiences". (Gorgorió et al., 2002, p. 24)

Transitions are on-going processes that begin as individuals make their entry into the organization, and continue till the time of their exit (Van Maanen \& Schein, 1979). Transitions may occur within the boundaries of a workplace, where employees continually adapt to emerging situations, or across different contexts, for instance, work and home (see Beach, 1999). Transitions entail not only day-to-day sociocultural adjustments and coping, but also function as "occasions for development" (Zittoun et al., 2003) whereby individuals develop new skills and functions, and learn new behaviors and practices. Some IT outsourcing research has explored how IT professionals adjust to changes in sociocultural circumstances. For example, as Upadhya and Vasavi (2006) note, well-travelled Indian IT professionals with exposure to global cultures blend "traditional" and "modern" values to negotiate their inherently traditional sociocultural home settings. They also show how families believing in "communitarian" social values are riddled with conflicts when individualized workplace cultures trickle into the wider community life. This strand of research has also reported on the sociocultural adjustments that individuals make within the workplace. For instance, D'Mello \& Eriksen (2010) studied how Indian IT professionals managed emotional strain on home and work relationships, resulting from long working hours tuned to distant time zones. They showed how individuals try to overcome stressful work environments by re-creating social relationships within 
the workplace to replace diminished social relationships outside the workplace. Such practices are commonplace in other professional settings as well. Individuals are known to create favourable and non-threatening work environments by building social networks and seeking social support (Feldman \& Brett, 1983; Kramer, 1993; Cooper-Thomas et al., 2011). Feldman \& Brett (1983) found that individuals actively seek and provide social support to colleagues in need. They also suggest that on the receiving side, social support seeking strategies are particularly prevalent among newcomers to the organization.

Newly hired employees are known to devise a range of strategies to reduce ambiguities and uncertainties in the work environment (Liu et al., 2015). Research in the identity literature, for instance Ibarra's (1999) study, examined how junior professionals crafted their professional identities as they transitioned into new work roles. Her study suggests that individuals seek out role models, experiment with different possible selves and then evaluate their performance through both external and internal feedback. Job crafting (Wrzesniewski \& Dutton, 2001) is another way in which individuals enhance feelings of control and proactively reduce ambiguity and threats (Matarelli \& Tagliaventi, 2012) in their work environment. Job crafting is a process whereby individuals redefine the meaning of their jobs to incorporate their own motives, passion and strengths (Wrzesniewski et al., 2010). Broadly, job crafting involves assessing and altering: (1) tasks by limiting or expanding the scope of the job; (2) relationships by changing the nature or extent of one's interaction with colleagues; and (3) perceptions by modifying the overall purpose of the job (ibid). Transitions also entail management of "boundaries" by employees who are often required to juggle work and non-work contexts that embody vastly different sociocultural realities (Lamont \& Molnár, 2002). Although the psychological response to boundaries may vary from person to person, research has found that individuals typically manage boundaries through "compartmentalization" or "segmentation" approaches and "integration" or "hybridization" approaches (Berry, 2003; Raghuram, 2013; Molinsky, 2013). In the former approach, employees are known to strictly separate work and home, i.e. they enact different practices, beliefs and values in the two sociocultural spheres. In the latter, employees merge or create a hybrid set of practices, beliefs and values, which are enacted in both spheres. In her study of 
Indian call center agents, Raghuram (2013) studied the impact of impression management (which mainly involved performing a Western identity in the workplace) on agents' work and non-work selves. The study revealed that some agents segmented their work and non-work identities in order to preserve their non-work identities. On the other hand, some agents created and enacted hybridized identities, absorbing cultural attitudes of western clients, experimenting with new possible selves and experiencing social freedoms such as living independently and exercising control over one's finances.

Transitions not only threaten and challenge individuals stepping into new sociocultural environments, but also signal periods of individual and collective learning. The cultural and social demands of a new work environment can cause reassessments of taken-for-granted customs, ways of living and doing, beliefs and practices. Finding a new balance and protecting the self then becomes a primary goal for individuals seeking to cope with the discomfort and challenges associated with displacement from the familiar (Zittoun et al., 2003). They gradually work out the hows and whats of adjustments, develop new practices, skills and capabilities to help survive and excel in the new environment (ibid). As we explain in the empirical sections, we found the transition management strategies highlighted in the above review and synthesis resonating particularly strongly in the experiences of our informants.

\section{IMPACT SOURCING AND SOCIOCULTURAL TRANSITIONS}

The ImS model of socially responsible outsourcing (Heeks, 2013) is a novel and emerging manifestation of the global digital economy. It now constitutes $12 \%$ of the total IT-BPO outsourcing market globally, amounting to nearly 235,000 workers ${ }^{2}$. It is also growing at a faster rate ( $11 \%$ year on year growth) than the traditional information technology \& business process outsourcing (IT-BPO) market. According to recent estimates, ImS can address a potential market of US $\$ 7.6$ billion by 2017 (NASSCOM, 2014). These advances have been made possible mainly by ICTs and

\footnotetext{
${ }^{2}$ These numbers include underprivileged individuals hired by ImS companies as well as traditional ITBPOs (see Everest Group (2014) for a detailed breakdown). Here, we specifically focus on ImS companies, i.e. companies established with the sole intention of employing underprivileged individuals.
} 
enhanced broadband connectivity in emerging economies. Recent figures show that nearly $94 \%$ of the world's population now receives a mobile phone signal, $48 \%$ are covered by mobile internet and nearly $28 \%$ have subscribed to a data package (Kende, 2015). Broadband coverage however is less impressive, but making good progress with nearly 711 million connections worldwide (Broadband commission, 2015). Such unprecedented digital connectivity has provided "well-meaning" entrepreneurs the opportunity to open outsourcing delivery centers even in far-flung rural areas.

In India, which is probably the most popular ImS destination, the practice began to take shape in 2006 when entrepreneurial IT-BPO professionals sensed a business opportunity to deliver low cost outsourcing work from the country's hinterlands. Since then, a number of ImS companies have sprung up across the country, a majority of them operating in rural and semi-urban areas (NASSCOM, 2014). Combined annual revenues of ImS companies in India add up to nearly US\$17 million and they employ nearly 6000 individuals between them. According to recent estimates the ImS market in India is expected to reach around US\$7.6 billion by the end of 2017 , generating over 80,000 jobs (ibid). Overall, practitioners and international donor agencies suggest that ImS companies can play a crucial role in providing underprivileged people mainstream employment opportunities and creating a positive impact on their quality of life. A small but growing number of studies have explored the ImS model, including its potential for influencing developmental and economic outcomes. Although this research does not explicitly analyze the challenges and processes of sociocultural transitions that situated individuals go through, a careful examination of recent articles hint at the challenges of sociocultural challenges and their management by ImS employees. For instance, Madon \& Sharanappa's (2013) work reveals how Indian ImS employees face challenges posed by patriarchal norms that view men as "bread earners" of the family and discourage women from working outside the home. Similarly, ImS employees are known to struggle when managing the everyday consequences of the inherent differences between their company's values and the local community's belief systems (Sinkovics et al., 2014; Sandeep \& Ravishankar, 2016). They could also find the professional team-based work environments of ImS companies (Lacity 
et al., 2014) and working with ICTs (Malik et al., 2013) overwhelming. In meeting such challenges, employees have been found to draw comfort and support from each other (Malik et al., 2013) and learn from observing the work of more experienced colleagues (Lacity et al., 2014). Research has also briefly documented the impact that ImS employment has had on different underprivileged and disadvantaged communities such as those living in rural areas (e.g., Madon \& Sharanappa, 2013; Malik et al., 2013), incarcerated individuals (e.g., Lacity et al., 2014) and indigenous groups (e.g., Lacity et al., 2011). Studies indicate that individual incomes go up by $80 \%-120 \%$ because of ImS salaries (Kubzansky et al., 2011; Heeks, 2013) and that the positive trickle down effects are also felt in the local communities (Sandeep and Ravishankar, 2016).

Scholars have conceptualized impact in this context as the behavioral and attitudinal changes individuals experience through their ImS employment, culminating in the development of capabilities (e.g., Madon \& Sharanappa, 2013). In line with the developmental studies literature, capabilities can be viewed as what each person "is able to do and to be" (Nussbaum, 2011, p.18). For instance, Madon \& Sharanappa (2013) found that ImS employees were able to communicate better, manage their finances and time better and tackle personal and professional problems more efficiently. Similarly, in Lacity et al.'s (2014) study of prison ImS, incarcerated individuals reported improvements in their social status, self-esteem and self-efficacy. Overall, these studies explain the social and economic potential of ImS and briefly highlight the positive impact ImS companies can have on underprivileged populations. However, ImS research is still in its early stages and there is scant in-depth research on how ImS employees manage sociocultural challenges in the process of transitioning to the ImS workplace and the developmental impacts of such a transition. For ImS employees, employment marks an important developmental phase in their personal and professional lives. As the wider management scholarship on organizational socialization has demonstrated, moving into a professional workplace can be a daunting experience (Van Maanen \& Schien, 1979). New sociocultural norms can seem baffling, and cultural adjustments, i.e., imbibing new values and beliefs, and enacting new practices, can be a source of stress and anguish. For ImS employees in rural India (the context of this study), the 
professional workplaces of ImS are in sharp cultural contrast to their traditional communities (Sandeep \& Ravishankar, 2016). Moreover, local communities are known to oppose ImS companies (NASSCOM, 2014; Sinkovics et al., 2014), framing their activities as cultural intrusions (Sandeep \& Ravishankar, 2015). For ImS employees caught between the two worlds, the process of imbibing new cultural material, which may openly contradict ingrained values and beliefs, is therefore not straightforward. As they establish themselves in the ImS work environment, employees strive to attain a new stability, developing new skills and capabilities in the process. These arguments provide the basis for the in-depth inductive analysis that follows in which we explore how ImS employees experience sociocultural transitions and the developmental impacts realized in this process. In particular, we explain how ImS employees respond to the challenges of undertaking digital work in rural India, and develop crucial capabilities. From a practical perspective, our insights into how ImS employees respond to new sociocultural contexts can help devise appropriate employee induction strategies, promote employee-driven socialization within ImS organizations and document the social impact of the ImS model.

\section{RESEARCH METHODS}

To understand how ImS employees experience and manage transitions, we focused on ImpactHub (a pseudonym), an ImS company based in the northern part of India. Adopting an interpretive approach (Walsham, 1995; Mayasandra et al., 2006), we conducted an in depth inductive qualitative case study of ImpactHub to understand the lived experiences (Ravishankar et al., 2010) of ImS employees. An interpretive approach emphasizes the social construction of reality and focuses on the intersubjective realities of actors (Walsham, 1995; Klein and Myers, 1999). Through the interpretive approach we tried to make sense of the individual and collective experience of the transitions of ImS employees. Concepts from the outsourcing, identity and the organizational socialization literatures served as "sensitizing lenses" (Walsham, 2006) during our fieldwork and data analysis. 


\section{Research setting}

ImpactHub, an up and coming Indian ImS company, was started in 2009 by two entrepreneurs with altruistic intentions of providing employment opportunities to underprivileged communities in the "hill" districts (i.e., rural areas) of the Himalayan region. The entrepreneurs hoped their "intervention" would help reduce the rampant outmigration of the communities' youth. Recent Indian census reports reveal that poor agricultural productivity and the perceived benefits of urban life have significantly contributed to economic outmigration in the region (Venkatesh, 2015). Nearly 1500 of the 15000 villages in the region are now uninhabited with people moving to the "plains" (i.e., urban areas) for employment opportunities (ibid). Rural areas have barely seen any productive economic activity, with two of the nine hilldistricts growing at a negative rate over the last decade. Despite a healthy literacy rate (see Table 1), inhabitants of the hill districts remain disadvantaged due to their geographical location, where primary healthcare and good educational institutions are virtually absent (ibid) and infrastructure to support large scale economic activity is lacking. The institutional and infrastructural lacunae is reflected in the household income in the hill districts - estimated to be $\$ 71$ per month per household (Mamgain \& Reddy, 2015), which is far below the national average. Recent studies have shown that hill districts fare poorly along several dimensions. For instance, Gupta's (2014) study, which uses indicators including income, infrastructure, health, education, employment and tourism, highlights a number of disparities. Overall, the hill districts are not in a good economic shape and offer limited employment opportunities for its people (Mamgain, 2016). Table 1 below compares districts in the hills and the plains along key socio-economic indicators.

\begin{tabular}{|l|l|l|}
\hline & \multicolumn{1}{|c|}{ Plains (Urban) } & \multicolumn{1}{|c|}{ Hills (Rural) } \\
\hline Literacy Rate & $78.67 \%$ & $80.08 \%$ \\
\hline Sex Ratio & 909 & 1056 \\
\hline Population & $6,190,623$ & $3,895,669$ \\
\hline Population Density & 556 & 116 \\
\hline Population Growth & $30.39 \%$ & $5.36 \%$ \\
\hline
\end{tabular}




\begin{tabular}{|l|l|l|}
\hline Unemployment rate - female per thousand & 142 & 108 \\
\hline Unemployment rate - male per thousand & 21 & 35 \\
\hline $\begin{array}{l}\text { \% Share of agriculture as a proportion of } \\
\text { the total local-economy }\end{array}$ & $\sim 10 \%$ & $\sim 80 \%$ \\
\hline $\begin{array}{l}\text { \% Of working population employed in the } \\
\text { primary sector (i.e., agriculture, } \\
\text { horticulture, floriculture) }\end{array}$ & $\sim 26 \%$ & $\sim 74 \%$ \\
\hline $\begin{array}{l}\text { Number of micro, small and medium } \\
\text { enterprises (as on 2012) }\end{array}$ & 20397 & 21295 \\
\hline $\begin{array}{l}\text { Investments in micro, small and medium } \\
\text { enterprises (as on 2012) }\end{array}$ & $\sim$ US\$1.09B ${ }^{3}$ & $\sim$ US\$75.92M \\
\hline $\begin{array}{l}\text { Number of people employed in micro, } \\
\text { small and medium enterprises (as on } \\
\text { 2012) }\end{array}$ & 149248 & 45993 \\
\hline $\begin{array}{l}\text { Number of large scale industries (as on } \\
\text { 2012) }\end{array}$ & 228 & $\sim$ US\$9.8M \\
\hline $\begin{array}{l}\text { Number of people employed in large scale } \\
\text { industries (as on 2012) }\end{array}$ & 84570 & 2 \\
\hline $\begin{array}{l}\text { Investments in large scale industries (as } \\
\text { on 2012) }\end{array}$ & $\sim$ US\$4.5B & 763 \\
\hline
\end{tabular}

Table 1. A comparison of districts in the hills and plains

(Source: Census of India 2010-11 (data.gov.in) and NSDC (2013))

In 2009, ImpactHub opened its first center in the hill districts, with 50 employees. At the time of our fieldwork the company operated a total of five centers in five different villages, all within a radius of 50 kilometres, employing close to 350 individuals. On average, there are around 300 households in each village. In this study we refer to the five villages collectively as "the community". Due to poor agricultural productivity and lack of employment opportunities, outmigration of the community's men has been rampant in recent years. Almost every other household has a male family member working in the nearby cities in low-wage service jobs such as security guards, household helps and drivers. As a consequence, the burden of working the land, collecting fodder for cattle and foraging forests has fallen upon on women, who in addition are responsible for household work such as

\footnotetext{
${ }^{3}$ Currency conversion rate as of Jan 2017: 1 Indian Rupee $=0.015$ US $\$$
} 
fetching water, cooking and general maintenance. However, this pattern seems to be changing slightly. The youth (both men and women) are now better educated than their parents, but their life choices have not yet significantly improved - the best career option for women as recounted by our informants would be a teaching position in primary schools run by the government; whereas the best that men can hope for is a job in the Indian army.

ImpactHub hires individuals from the local community and trains them on IT and managerial skills to provide digitally-enabled, back office services to domestic and international clients. The type of work done here is typical of most IT-BPOs, specializing across sectors such as banking and financial services, insurance, publishing and telecom. Services provided include XML-tagging, digitization, creating e-books, XBRL-based work and other business process specific work. To manage its workflow, ImpactHub adopts what is popularly termed as a distributed delivery model (see Figure 1).

$\longrightarrow$ Flow of communication

$---->$ Flow of data

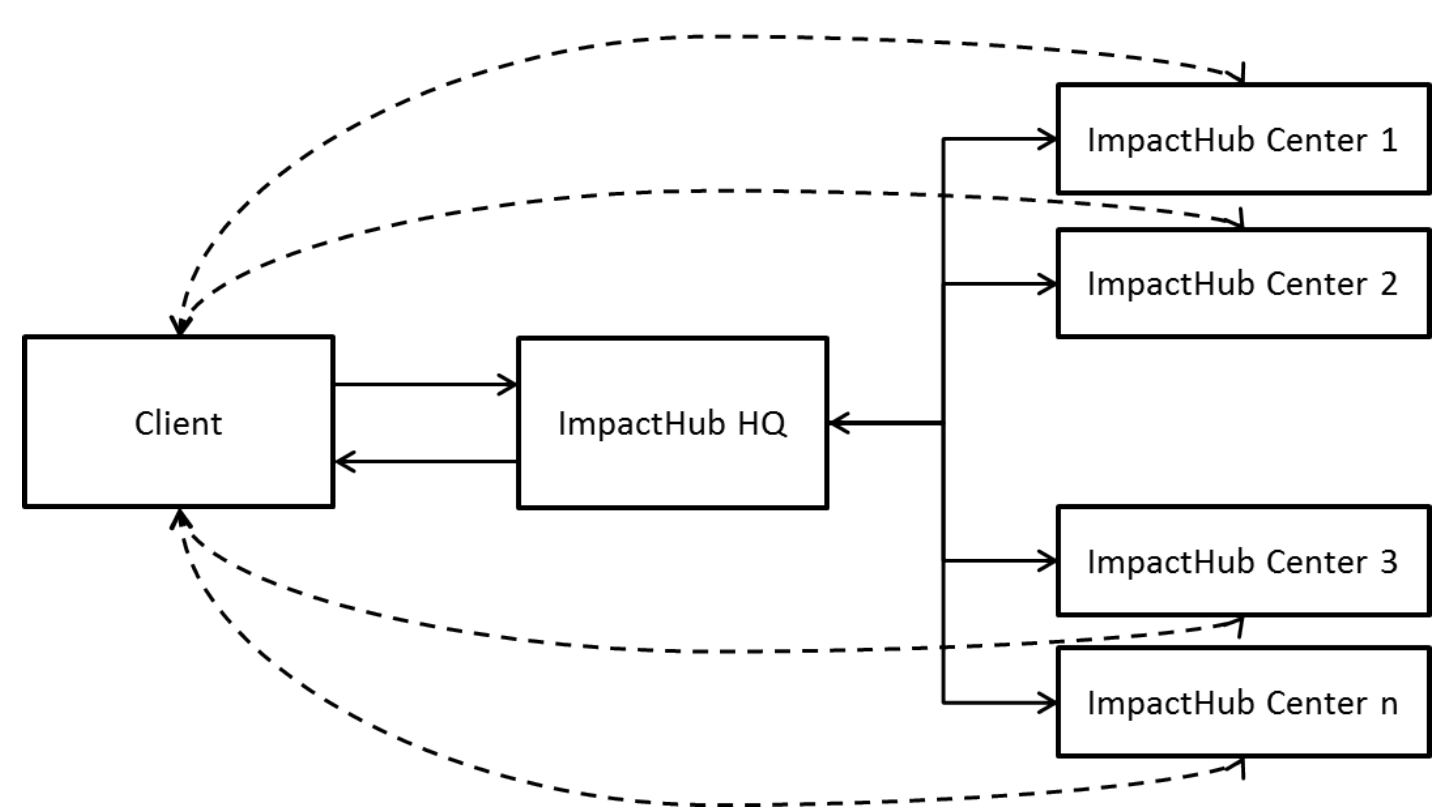

Figure 1. Distributed Delivery in ImpactHub

Here, ImpactHub's HQ located in a large Indian city manages client-side relationships, including marketing, business development and other high-level managerial tasks. The outsourced work from the client is undertaken in one of 
ImpactHub's many centers. Typically, a complex project is broken down into smaller chunks and distributed to the centers, where the actual work is carried out. The smaller chunks (popularly referred to as "microwork") are then collated and sent back to the client. ImpactHub manages data integrity and security through accesscontrolled shared folders using cloud-based technology.

Employee recruitment is through a written test followed by an interview. Once hired, employees undergo a three-month formal training program. The training period begins with a week of socialization activities where they are introduced to the company's norms and values. Here, they are taught to align their personal values with those of the organization (for e.g., time sense and punctuality, total commitment to meeting deadlines and respecting team members and team leaders). They are also taught how to socialize within the office environment, (for e.g., greeting each other with handshakes and hugs). Employees are then trained to improve their computer literacy, spoken and written English, and also given "process training". Process training focuses on specific skills required to perform the outsourced tasks. Different projects require employees to adopt different processes or workflows. For instance, the workflow for data entry is different from that for desktop publishing. After their training employees are assigned to teams that perform outsourced business process management projects. Typically, they begin as "process-trainees" and can move up the ranks into managerial positions.

The corporate culture of ImpactHub is very different from what can be described as the community's culture. As we observed in our fieldwork, the liberal values, beliefs and practices embodied in the ImpactHub's culture was in stark opposition to the more conservative values, beliefs and practices held by the community. Table 2 contrasts cultural features of the community with that of ImpactHub. Our intention in outlining these differences is not to set off a binary opposition. The differences noted in the table are probably best interpreted as broad strokes of cultural differences and not as rigid categorizations of ImpactHub and the community. In reality, the community and ImpactHub are heterogeneous agglomerations representing individuals with different political interests, beliefs and values. However, these distinctions (Table 2) are consistent with how our 
informants portrayed the respective cultural worlds, i.e. the values, beliefs and practices of the community and ImpactHub.

\begin{tabular}{|c|c|c|}
\hline & Community & ImpactHub \\
\hline \multirow[t]{6}{*}{$\begin{array}{l}\text { Values and } \\
\text { beliefs }\end{array}$} & Men are more capable than women & $\begin{array}{l}\text { Men and women are equal in all } \\
\text { respects }\end{array}$ \\
\hline & $\begin{array}{l}\text { Women's rightful "place" is within the } \\
\text { household and in the agricultural } \\
\text { fields }\end{array}$ & Women can be who they want to be \\
\hline & Elders are better decision makers & $\begin{array}{l}\text { Decisions should be taken } \\
\text { democratically and everyone should } \\
\text { have a say }\end{array}$ \\
\hline & $\begin{array}{l}\text { Men and women should not socialize } \\
\text { with each other }\end{array}$ & $\begin{array}{l}\text { Men and women should be able to } \\
\text { freely socialize with each other }\end{array}$ \\
\hline & $\begin{array}{l}\text { Men and women should behave } \\
\text { modestly, conforming to "community } \\
\text { standards" }\end{array}$ & $\begin{array}{l}\text { Men and women can do as they } \\
\text { please as long as they don't flout } \\
\text { organizational norms }\end{array}$ \\
\hline & $\begin{array}{l}\text { Individuals should follow the } \\
\text { traditional conservative values of the } \\
\text { community }\end{array}$ & $\begin{array}{l}\text { Individuals should adopt liberal } \\
\text { values, which also leads to } \\
\text { empowerment }\end{array}$ \\
\hline \multirow[t]{4}{*}{ Practices } & Gendered division of labour & $\begin{array}{l}\text { Ability and interest-based division of } \\
\text { labour }\end{array}$ \\
\hline & $\begin{array}{l}\text { Restricted socialization of men and } \\
\text { women }\end{array}$ & $\begin{array}{l}\text { Men and women work together, } \\
\text { share space and collaborate on } \\
\text { projects }\end{array}$ \\
\hline & $\begin{array}{l}\text { Entitlements based on the caste and } \\
\text { social standing of the individual }\end{array}$ & Merit-based entitlements \\
\hline & $\begin{array}{l}\text { Ostracize individuals who transgress } \\
\text { community traditions }\end{array}$ & $\begin{array}{l}\text { Employees are evaluated according } \\
\text { to organizational norms }\end{array}$ \\
\hline
\end{tabular}

Table 2. Community and ImpactHub: Values, beliefs and practices

\section{Data sources}

Researchers adopting the case study approach spend time in the field interacting with their informants via semi-structured and open-ended interviews, as well as via participant and non-participant observations (Yin, 1994). In line with this tradition, our research was primarily informed by empirical material collected over six months of in-depth fieldwork (from March 2013 to August 2013). We collected data through open-ended interviews and non-participant observations. Table 3 provides an overview of our fieldwork. We interacted with 25 employees of ImpactHub in five centers. The average age of our informants was 21 years and their tenures in the company ranged from one month to three years. We also had conversations with members of the community and ImpactHub leadership during our fieldwork. Our intensive fieldwork included a fortnight's stay in the community 
where ImpactHub centers are located. We also conducted several follow up Skype and telephone conversations with our informants. We hung out with ImpactHub employees, attended team meetings, observed and sometimes participated in the daily "team huddles". We also attended village committee meetings, where ImpactHub's senior managers and the village elders discussed the company's contribution to the community.

\begin{tabular}{|l|c|c|c|c|c|}
\hline & Center 1 & Center 2 & Center 3 & Center 4 & Center 5 \\
\hline $\begin{array}{l}\text { Number of days of } \\
\text { fieldwork }\end{array}$ & 3 & 3 & 4 & 2 & 2 \\
\hline Male informants & 2 & 2 & 2 & 1 & 0 \\
\hline Female informants & 3 & 5 & 7 & 2 & 1 \\
\hline $\begin{array}{l}\text { Total hours of semi- } \\
\text { structured interviews } \\
\text { with ImpactHub } \\
\text { employees }\end{array}$ & 3 & 6 & 6 & 3 & 1 \\
\hline $\begin{array}{l}\text { Total hours of } \\
\text { unstructured } \\
\text { interviews with } \\
\text { ImpactHub } \\
\text { employees and } \\
\text { community members }\end{array}$ & 4 & 4 & 6 & 2 & \\
\hline
\end{tabular}

Table 3. Overview of Fieldwork

We conducted semi-structured and unstructured interviews with ImpactHub employees, their family members and members of the local community. Each semistructured interview lasted between 15 minutes and one hour while each unstructured interview (or conversation) lasted longer - up to two hours. Semistructured interviews were conducted in ImpactHub centers while unstructured interviews with ImpactHub employees and community members were conducted in public spaces. Interviews were conducted in Hindi and English. These interviews were recorded, transcribed and translated from Hindi to English, whenever needed. Detailed notes about conversations with informants were made at the end of each day of fieldwork.

\section{Data analysis}

Data analysis was conducted over three stages. In the first stage we compiled our empirical material comprising of: (1) informants' lived experience of working for ImpactHub, (2) observations of team meetings at ImpactHub and (3) 
notes taken during the fieldwork. In the second stage, we conducted a thorough analysis of this database with the broad aim of identifying the challenges of sociocultural transitions and our informants' strategic responses.

First-order codes

Theoretical categories

Aggregate theoretical dimensions

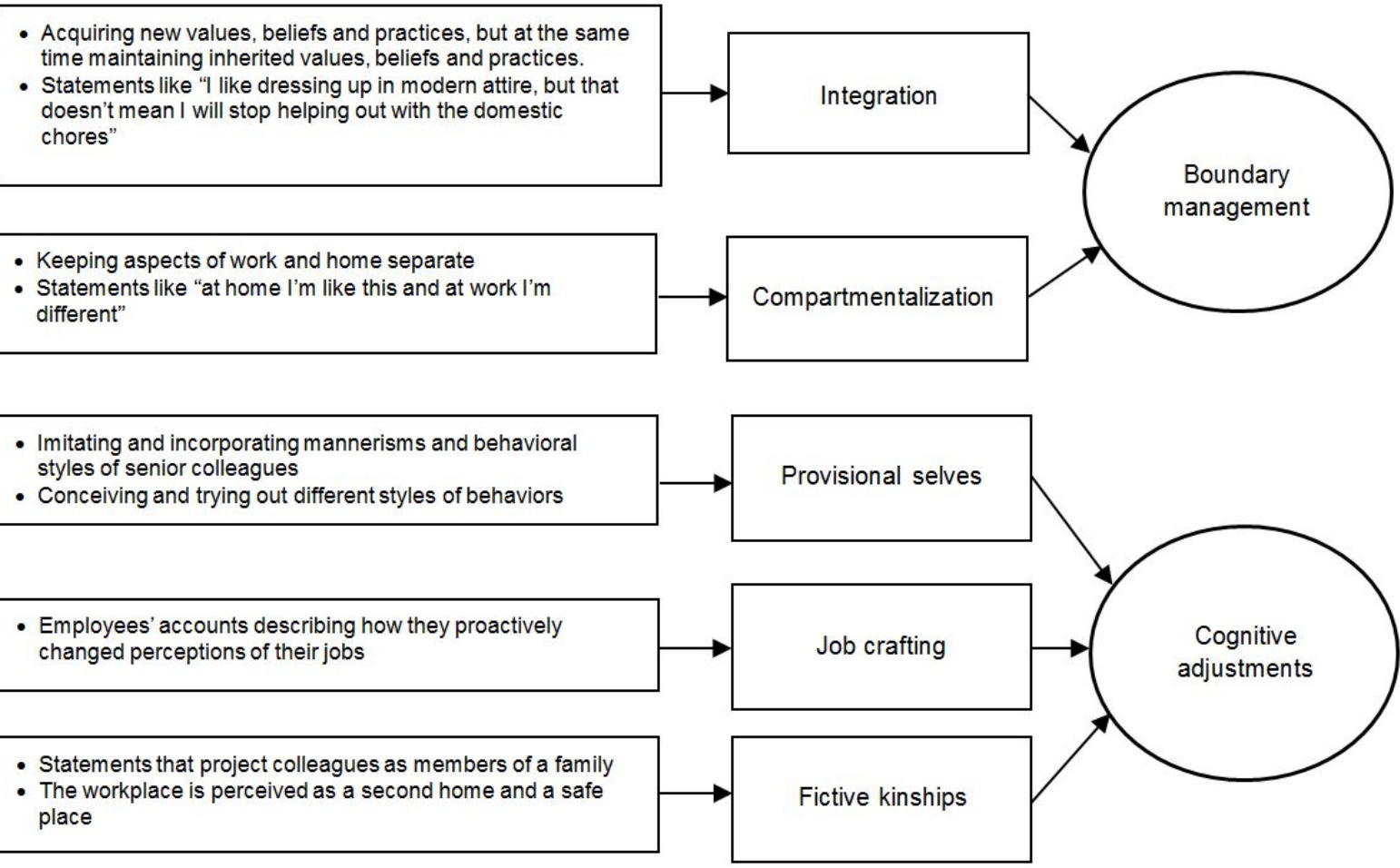

Figure 2. Sociocultural transition strategies: first-order codes, theoretical categories and aggregate theoretical dimensions

The second stage comprised of three steps. In the first step, we broadly categorized the empirical material into three groups: (a) transition challenges faced by ImpactHub employees, (b) strategies developed by ImpactHub employees and (c) self-reported "impact" during employees' tenure. We began with a process of open coding (Locke, 2001) by sifting through our informants' statements about their experience of working in ImpactHub, and statements that related to managing or coping with the challenges of transitioning to the workplace. Through this process we drew up first-order codes by combining different codes that reflected similar ideas and themes. In the second step we moved to axial coding (Strauss \& Corbin, 1998), and here our codes or categories became more abstract, generating theoretical categories. In this step we also consulted scholarship on outsourcing, 
identity and organizational socialization (which were our sensitizing lenses) to match emerging categories with extant concepts. For instance, drawing on the work of Ibarra (1999) we coded informants' statements about how they tried out different behavioral styles and mannerisms as "provisional selves". We derived a total of five theoretical categories to represent the transition strategies (see Figure 2). In the last step, we looked for commonalities between our theoretical categories and created "aggregate theoretical dimensions" (Pratt et al., 2006) of transition strategies. The theoretical categories of "compartmentalization" and "integration" illustrated boundary management by our informants; while "provisional selves", "fictive kinships" and "job crafting" showed cognitive adjustments (see Figure 2).

In the third stage, we shifted our focus to the impact of transitions on ImpactHub employees. We conceptualized "impact" as the behavioral and attitudinal changes that individuals experienced while managing transition challenges. We again followed the process of open and axial coding to derive firstorder codes and theoretical categories respectively. The theoretical categories reflected newly developed capabilities, referring to those newly acquired behaviors, skills and attitudes developed by individuals as they learnt to manage transitions. We aggregated the theoretical categories into individual and collective capabilities. Figure 3 provides a summary of the data structure relating to impact. 
- Working with different types of colleagues

- Handling difficult situations at home and the community

- Statements like "I can even work with people I don't get along"

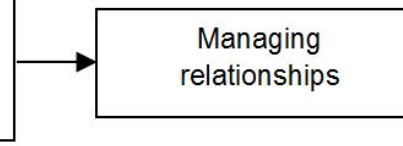

- Express oneself confidently in professional and personal situations

- Statements like "I can now voice my concerns at office and home"

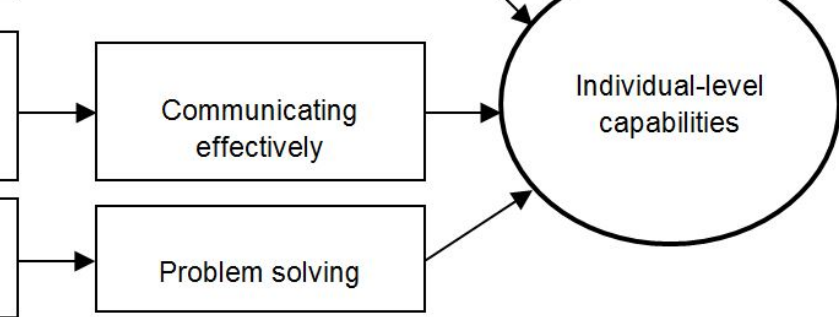

- Statements like "I couldn't think through difficult situations

earlier, but now I am more comfortable"

- Democratically arrive at decisions

- Statements like "we're a family, we respect and listen to each other's opinion"
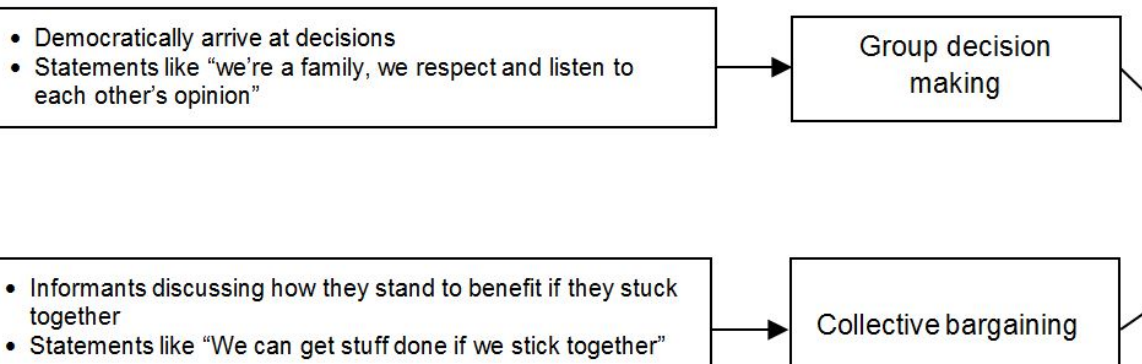

- Informants discussing how they stand to benefit if they stuck together

- Statements like "We can get stuff done if we stick together"

\section{Collective bargaining}

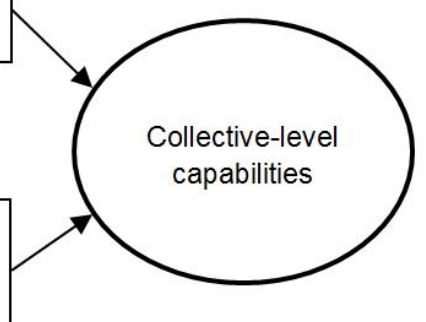

Figure 3. Impact of managing transitions: first-order codes, theoretical categories and aggregate theoretical dimensions

\section{ANALYSIS}

The empirical material revealed that ImpactHub employees faced numerous challenges once they started working at the relatively modern ImpactHub workplace. The analysis below explains the various strategies they adopted as they met the challenges and transitioned from their community background and experiences to the ImpactHub environment. The analysis ends with an elaboration of the capabilities developed by ImS employees as a result of navigating these transitions.

\section{Us and them: Problems of boundary management}

An excerpt from our field notes:

Location: A sweetmeat shop close to ImpactHub, Center 1: 'These are very different times now' remarks Ramesh, the 42-year-old owner of the shop in a resigned tone. 'It is kalyug [a time of decadence] my friend'. Signalling with his eyes, he gestures one of his customers to pay attention to the scene across the street. Two young men are sitting on a motorbike with their gaze directed towards the ImpactHub 
office. 'They come here often, sometimes stare at the girls and create trouble...they're a nuisance'. The friend turns to Ramesh and adds impatiently, 'They may be a nuisance...but look at the girls in their flashy clothes and 'film-y' glasses'. An elderly customer who is quietly watching the proceedings from a corner breaks his silence with an angry 'we never had this city culture before! What else did you expect would happen? Our village resembles a Bollywood movie set. Youngsters these days know no limits; we should teach them better. Ramesh nods in agreement as he packs a sweetmeat for one of his waiting customers.

The belief that ImpactHub was a "cultural encroachment", i.e. belonging to and representative of the decadent culture of the city was widespread in the community. ImpactHub with its liberal values, beliefs and practices (see Table 2), was at odds with the community's traditional moorings. Stray incidents and popular beliefs about the city culture, more specifically the youth culture of BPOs in cities shaped the community's imagination. Furthermore, themes in popular Bollywood movies, relating to the nature of work and the organizational culture of BPOs significantly influenced perceptions. Community members drew on such easy-to-access stereotypes to make sense of ImpactHub. The senior management of ImpactHub, on the other hand, felt strongly that the community's conservative mind-set was a huge stumbling block for progress. They believed that ImpactHub was altruistically motivated and would inevitably disrupt institutionalized norms and dislodge status quos.

What we are creating here is not just employment. We are also making sure that individuals develop and transform into independent, strong, responsible citizens. Giving opportunities to women is especially important. In fact, they make up a majority of our workforce in every center. In a way we are in the business of creating choice. That is what we do, that is our idea of empowerment. There is a general feeling among the community that we are changing the ethos of the place - that we are bringing the culture of the city, but 
this resistance is expected. What they are seeing is new, we are challenging some of the status quos and there is bound to be some noise. [ImpactHub senior manager, informant \#1M${ }^{4}$ ]

ImpactHub management believed in their mission of empowerment and were keen on "bringing jobs to the community's doorsteps". The contrasting worldviews of the community and ImpactHub management created what could be termed as "symbolic boundaries" between them (Lamont \& Molnár, 2002). These boundaries had important implications for employees, exposing them to the intense scrutiny of community members.

Even when I'm out in the community, I am regarded as an employee of ImpactHub...I carry this identity (the ImpactHub identity) around with me wherever I go ... people in the community often comment that I am one of 'them' (i.e. an ImpactHub employee) when I am passing through public spaces. [ImpactHub informant \#4M]

Informants explained that they experienced significant psychological stress because of the differing sociocultural expectations of the community and the ImpactHub workplace. Our informants crafted two strategies in response to the challenges the symbolic boundaries posed. The strategies that will be described, i.e. compartmentalization and integration, can be viewed as two extreme poles of a continuum, rather than as rigid categorizations - with individuals adopting them in varying degrees at different times. In this sense the two strategies represent "ideal types" - characteristics most commonly seen in their respective cases.

\section{Compartmentalization strategy}

Informants adopting this strategy developed context-appropriate responses to manage boundaries between work and home. At work, they embraced the practices and beliefs espoused within ImpactHub; in their homes and in community spaces, they aligned themselves to the community's beliefs, norms and practices. Such a strategy of compartmentalizing specific behaviors was described as follows.

\footnotetext{
4 Throughout the paper we have used this notation style to identify, and attribute quotes to informants. Here informant \#1M refers to our first informant and identifies the informant as male.
} 
When I am in the office I am like how everyone else is...I don't want to be left out...but when I am in the community I am how I am expected to be...should live according to the customs of the hills (as opposed to the "plains"). [ImpactHub informant \#21M]

Research suggests that individuals try hard to demonstrate highly contextappropriate mannerisms when faced with the challenges of learning a second culture (LaFromboise et al., 1993). Informants adopting the compartmentalization strategy drew a clear distinction between home and work - they reserved certain kinds of behaviors for use in their home environment and others for use in their workplace. The motivation for adopting this strategy varied among our informants. For some, acting out two sets of behaviors came as a moral obligation - they respected the community and believed it was important not to mix the contrasting cultural worlds. For others, compartmentalization was less about moral obligation and more about judiciously adopting non-confrontational behaviors. In both cases, they carefully calibrated their everyday behaviors to meet the expectations at work and home. We found in our analysis that individuals adopting the compartmentalization strategy were, relatively speaking, newcomers to the organization.h Invariably lacking in confidence and unsure about the ImpactHub culture, they chose to compartmentalize their behavior, as it was a seemingly safer strategy that did not draw any unwanted negative attention.

\section{Integration strategy}

At the other end of the spectrum was what we may refer to as an integration strategy. Employing this strategy, individuals tried to blend the behaviors they learnt at ImpactHub with their inherited traditions, creating a hybrid personality. They incorporated workplace behaviors in their personal lives (for e.g., openly voicing their opinions at home, socializing with the other gender in public spaces and dressing up in "modern" attire).

If I think we are doing something wrong, or if we can improve the process I always speak up. I now know the importance of being heard and to speak up for what I think is right... because not speaking affects you. Even in my family whenever they are taking major 
decisions I make it a point to make my voice heard. [ImpactHub informant \#8F]

This informant was particularly cognizant of these attitudinal changes in herself and further added:

I know my parents don't always approve of my thinking...but I also

know my limits. I do not go overboard. [ImpactHub informant \#8F]

While some of our informants (like the informant \#8F above) tried to exercise self-control over the extent to which they flouted the community's norms, others were blasé about the potential fall-out of their integration efforts. To the latter group, employment at ImpactHub was an opportunity to discover and try out a new lifestyle and they did so without worrying too much about the consequences. Informants adopting the integration strategy thus went against the community's social norms in varying degrees. These behavioral changes were not well received by the community, including sometimes by the informants' own family members. Adopting the integration strategy therefore often meant a mobilization of informants' inner agency against the community's social order.

At least once a week my mother has a complaint to narrate. One day it's come from the neighbour, the second day it is from the temple priest, the third day it is from a relative...this one time my mother was so upset because there was a rumour circulating that I had boyfriend...I know who they are referring to... but he is just a friend. Just because I spend time with him doesn't mean anything. [ImpactHub informant\#5F]

Our analysis showed that many of our informants adopting the integration strategy had held longer tenures at the time of our fieldwork. However, when they were newcomers to the organization the same informants had adopted the seemingly safer compartmentalization strategy detailed earlier.

When I first joined ImpactHub I was careful not to displease anyone at home or work...but slowly I gained the confidence to be myself both at work and at home. [ImpactHub informant \#19F] 


\section{Making cognitive adjustments in the workplace}

Given their underprivileged and economically disadvantaged rural background, a majority of our informants, despite being college graduates on paper, had little or no experience of a professional environment. They found several aspects of the new ImpactHub environment intimidating, such as working and sharing space with the other gender, working with ICTs and adhering to workplace norms.

During the first day of our orientation all the boys ran to one part of the room and us girls ran to the other! There was so much hesitation to talk and to make eye contact. [ImpactHub informant \#2F]

New entrants had to quickly pick up new styles of behavior and practices espoused and held in high regard at ImpactHub. The professional ethic of the workplace, working in teams and meeting deadlines - it was all novel, and often intimidating.

I had never worked in teams...never worked alongside men...I was not used to shaking hands, let alone giving a hug! I found it all very strange...these new things were baffling to me at first! I felt like I had entered a new world altogether. [ImpactHub informant \#6F]

Our informants also recounted the difficulties of working with ICTs and learning corporate jargon. Most of our informants had limited experience of working with computers, although a few owned low-cost Chinese smartphones that had entered the rural markets. Further, although the working language at ImpactHub was Hindi, informants struggled to come to terms with the management jargon often used at work:

I was very afraid initially... I lived and worked with fear. I was a salesman in a Kashmiri handicrafts shop earlier...I had no confidence that I could work with computers. Everyone at work seemed to speak in a "language" I could not understand although they were speaking in Hindi! [ImpactHub informant \#8M]

Below, we describe three key cognitive adjustment strategies ImpactHub employees adopted as they aligned themselves to the practices and norms of their workplace. 


\section{Developing fictive kinships}

The literature suggests that developing social bonds and networks is one way of overcoming anxieties at the workplace (Cooper-Thomas et al., 2011; Feldman and Brett, 1983). In a similar vein, ImpactHub employees built strong social bonds with their peers and found both emotional and job-related support in such relationships. Informant \#6F, while recounting how she felt when she had to move from one ImpactHub center to another, remarked:

We are like a family here. When I was moved from the previous center, I cried so much! I did not even cry that much when I left home the first time! My colleagues are more than just my colleagues...they are my family, my brothers and sisters. They give me confidence and encourage me to do better. [ImpactHub informant \#6F]

Our informants considered each other members of the same family, and not merely colleagues. They often invoked the word "family" to collectively refer to their colleagues. There was also an informal hierarchy of social relations at play, with senior colleagues assuming personal responsibility for the protection and care of junior colleagues. The juniors often referred to senior male colleagues as bhaiyya (brother) or "sir" and senior female colleagues as "ma'am". Furthermore, the juniors also used respect-signifying personal pronouns in Hindi such as "aap", while addressing the seniors.

I often hear that in urban BPOs people come today and leave tomorrow. Here it is different. Once you join the company, you have joined our family... we look after each other here, be it technical issues, family issues or even financial issues...We help each other as much as possible. [ImpactHub informant \#22M]

The employee attrition rate at ImpactHub was low and the strong social bonds played a crucial role in influencing loyalty. This kind of social formation closely resembles the idea of a fictive kinship or pseudo-families (Ogbu, 1991). In a fictive kinship individuals come together for a specific purpose (Tierney \& Venegas, 2006) and in the case of ImpactHub, the basis for the emergence and development of fictive kinships was driven by the employees' need to survive in a culturally alien 
setting. The social bonds that we observed at ImpactHub were in some respects similar to collegial relationships reported in IT-BPO settings (for e.g., see D'Mello \& Eriksen, 2010), but arguably more cohesive. Moreover, these relationships were enduring and lasted beyond employees' tenure in a particular ImpactHub center and in some cases beyond their employment at ImpactHub.

\section{Experimenting with provisional selves}

Having grown up in rural areas, with limited exposure to "city culture" and to the "professional" culture of the modern workplace, many of our informants felt they lacked the social skills to function effectively at ImpactHub. They recognized the importance of broadening their cultural repertoire and picking up social skills.

During the first two weeks of induction I observed a lot... how people spoke, how they interacted with their Team Leads and also during our morning huddles - how people discussed issues and what they spoke about. Also how they greeted each other, hugged and shook hands... and then I tried in practice what I observed. [ImpactHub informant \#25M]

In order to learn and perfect new mannerisms, our informants resorted to what Ibarra (1999) has called "experimenting with provisional selves". The selves they experimented with (for instance, the behaviors and mannerisms associated with an extrovertish senior manager) were "provisional", i.e. in a state of constant evolution and change. Informants discarded aspects they weren't comfortable with, and retained those they felt confident enacting. We found this method of learning through experimentation, i.e. through observation and mimicking, common among our informants. They observed and learnt from colleagues who were considered as role models and mentors in the organization. They learnt not only the technical aspects of their job but also picked up behavioral cues for different work situations such as team meetings and informal chats. In this manner, informants constructed different "templates of selves" that helped them enact context-appropriate behaviors and mannerisms. The degree of mimicry, of course, varied from informant to informant. At one end of the spectrum were informants who tried to mix into the fold elements of their own style, while at the other end informants played safe and stuck to 
imitating what they observed and felt were appropriate mannerisms. In general, as self-efficacy improved, informants brought in their own styles of behavior. They also regularly assessed their own "performances" to make sure they were on the right track.

I should probably talk a little less. I sometimes tend to go overboard with my opinions and it has landed me in trouble. [ImpactHub informant \#7M]

\section{Engaging in job crafting}

Employment at ImpactHub was the only viable career option for many in the community, but it wasn't an easy option. As noted earlier, few informants had any prior experience of working in a professional environment. This often led our informants to self-doubt - they questioned their own abilities and wondered if they were even fit for the job. Some even contemplated quitting.

I wasn't sure if I'd survive three months. The first two or three weeks were very stressful. I remember going back home and thinking seriously if I should continue with the job. I was very disillusioned. [ImpactHub informant \#8F]

Many informants explained that they adapted by reframing their challenging job in a positive light. The literature suggests that positive reframing is one useful way of regaining and enhancing control over difficult situations (Ashford \& Black, 1996). Such a positive reframing or cognitive recrafting of their job (Wrzesniewski \& Dutton, 2001; Berg et al., 2010) gave our informants a renewed sense of purpose and duty, displacing their fears and apprehensions.

This job has given my family and me a sense of pride and dignity. It is not easy to earn this. This is what keeps me going on. It is bigger than my own needs. Now my sister can go to a better school...I can afford to pay for my own wedding expenses. These luxuries wouldn't have been possible without this job. [ImpactHub informant \#15F] 
For a minority of our informants, ImpactHub wasn't the "dream" job. The most desirable employer, for some of our male informants, was the Indian army. The community had a long history of being a recruitment hotspot for the army. Thus, for some informants the ImpactHub job was simply an opportunity to pick up some transferable skills for later use in their army job. They cognitively recrafted the meaning the ImpactHub job held for them, attributing a bigger purpose to it.

In the army leadership skills are very important. I can expose myself to situations here too. I try to take up leadership roles in small ways like organizing events and taking initiative during team meetings. This way I also know where I am lacking and where I need to improve. [ImpactHub informant \#7M]

\section{Development of individual-level capabilities}

In the process of managing the challenges and conflicts associated with their transition to the ImpactHub environment, our informants reported that they developed several new capabilities, which enabled them to exert greater control over their personal and professional lives.

\section{Managing relationships}

As many of our informants recounted, working in ImpactHub put them into situations that required careful handling of the particular expectations of a disparate and heterogeneous audience (e.g., their family members, the community, ImpactHub team members and ImpactHub management). This experience helped them to learn the art of effectively managing professional and personal relationships. They now felt they had greater control over their life.

Last week we were discussing how to allocate work in the team meeting. But I had some work at home which needed my attention...my TL (team lead) told me that I could take a couple of days off but my other team members had to agree since they would have to take my work load... and I managed to convince them. Earlier, I wouldn't have uttered a word; I'd just get on with it and be silent. [ImpactHub informant\#24M] 


\section{Communicating effectively}

ImpactHub provided ample opportunities for employees to develop their communication skills and our informants reported substantial improvements in this regard. As previously mentioned, they had to manage the expectations of a diverse audience, which necessitated the use of different types of communication for different contexts.

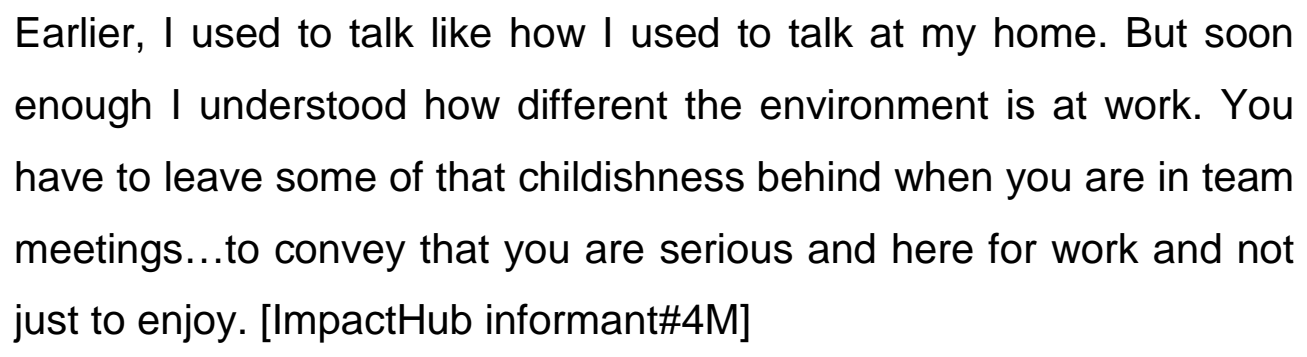

Communicating professionally was a skill that our informants valued highly. They understood the importance of projecting a professional image at the workplace and the repercussions of failing to do so. Also, employees who aspired to move on to other jobs saw communication skills as an important transferable skill.

\section{Problem-solving}

Our informants reported that a constant inflow of challenging tasks at work helped them exercise their cognitive abilities and develop problem-solving skills.

Sometimes I think life was so simple earlier. Now, there are issues on a day-to-day basis - mostly at work - that demands constant attention. Of course this is more fun... I am not idle at all. Even when I go back home I'm thinking about the open issues at work. [ImpactHub informant\#17F]

Informants reported that their problem-solving skills had vastly improved.

I can organize my thinking better. Whenever there is an issue now I know how to go about looking for a solution. [ImpactHub informant \#6F]

In sum, many of our informants developed problem-solving skills that proved useful in different situations, both at work and at home. They reported that their social 
standing within the community had also significantly improved, as they were now perceived as being capable of offering advice on a variety of matters.

\section{Development of collective-level capabilities}

Our empirical material also suggested a second type of capability developed by our informants, which may be termed as collective-level capabilities. Research suggests that such capabilities are developed socially through interactions between group members (Comim \& Carey, 2001) and are more than just the sum total of individual-level capabilities.

\section{Group decision-making}

The day we start telling ourselves, “well, this won't affect me, why should I bother"... thinking selfishly only about ourselves and not collectively for the whole group, we cannot progress. We have to move forward as a group by listening to each other, and understanding each other's fears and desires. [ImpactHub informant \#8M]

Prior to joining ImpactHub, our informants had little experience of working and socializing in a professional team. With the ImpactHub experience they explained that they now internalized the true meaning of consensus-building and democracy and learned to appreciate differences of opinions. They enjoyed the process of deliberating and reaching collective decisions, which they felt would lead to the greater good of ImpactHub.

\section{Collective bargaining}

With improved self-confidence and a sense of group solidarity, informants questioned the status quos both at work and in their community and in the process realized that they would have a greater say if they worked as a group.

For some of us, reaching the workplace early in the morning is difficult. There are people, including myself, who live $10 \mathrm{~km}$ away and finishing household chores and making it on time is a problem. We got together and discussed this issue and decided to talk to the 
management about making the working hours a bit more flexible.

[ImpactHub informants \#19F]

In this instance, informants realized the benefit of bringing a practical problem to the senior management's notice, collectively as a group, rather than individually. Overall, informants reported that they had now developed, in significant measure, the capability to bargain and take collective action to resolve problems. They further explained they now came together as a group and represented their collective interests when negotiating with the community.

\section{DISCUSSION}

The analysis above suggests that sociocultural transitions triggered by the ImS business model can be a cognitively and psychologically demanding experience for its direct beneficiaries. ImS employees face up to serious misalignments between the belief systems embodied in the workplace and their highly traditional communities. They may also find themselves lacking the contextual intelligence required to navigate the normative expectations of their professional outsourcing work setting.

\section{Strategies for managing sociocultural transitions}

As we found in our case, informants employed a series of strategies to respond and manage the symbolic boundaries between their community and their ImS work environment. First, they used compartmentalization and integration strategies to regulate their behavior in the community and at work. These findings concur with Raghuram's (2013) study of urban Indian call center employees, where she found similar patterns of behavior among her informants. However, unlike Raghuram's (2013) findings, which found pressures of dealing with demanding western customers on the phone and a desire to preserve Indian identities at the heart of call center employees' strategic responses, it seems that the drivers are different in rural ImS settings. ImpactHub employees adopted the compartmentalization strategy either as a moral obligation or to minimize all possible confrontation scenarios in their interactions within the community and at ImpactHub. In this behavioral strategy they appeared to be following one of the most basic tenets 
of self-presentation and impression management - making sure that those before whom they play one part will not be the same individuals before whom they play a different part in another setting (Goffman, 1959, p. 57). On the other hand, ImpactHub employees employing the integration approach simply went with the flow, experiencing and enacting their evolving selves. Thus, we would argue that the former category of informants was deeply fearful of upsetting the community's social order and structural features. The latter category, by contrast, seemed to be demonstrating a greater degree of agency and engaging in what is increasingly being termed as institutional work - actions that potentially transform social structure (see Lawrence et al., 2009). Raghuram (2013) suggests that integration strategies are normally seen in employees with longer tenures. The argument here is that with the confidence of work experience behind them, individuals are more likely to assert themselves and are less likely to be torn between "tradition" and "modernity". The findings from our case support this argument: ImpactHub employees with longer tenures tended to adopt the integration strategy, while new entrants played it safe by compartmentalizing. Sociocultural transition strategies are thus, dynamic in nature. At different stages of transitioning, ImS employees may turn to different strategies in line with their built up experiences in the community and the workplace. An important feature of the dynamic transitioning process at ImpactHub was the gradual empowering of many employees, who felt sufficiently confident to enact an integrated rather than a compartmentalized self.

Second, our analysis demonstrated how cognitive adjustments were central to ImS employees' sociocultural transitions. Specifically, the empirical material showed three different strategies of cognitive adjustments: experimenting with provisional selves, creating fictive kinships and engaging in job crafting. Organizations invariably prescribe norms for "appropriate mannerisms, attitudes and social rituals" (Van Maanen \& Schein, 1979, p.226) that new entrants are expected to learn and internalize. While organizations state broad objectives that need to be achieved in a role, rarely do they specify how to go about accomplishing those goals (Liu et al., 2015). In the specific case of ImS, given that employees often walk into an extremely unfamiliar cultural terrain at work, they find it an even bigger struggle adapting to new roles, learning new behaviors and building professional networks. Thus, as we 
found in our study, ImS employees initiated a process of experimenting with provisional selves (Ibarra, 1999) in order to align their behaviors with the ImS work setting. They also cognitively reframed what the ImS job meant to them (for e.g., by assigning it a higher purpose). The literature suggests that such job crafting is a coping strategy used by individuals to take better control of their professional and personal lives (see Matarelli \& Tagliaventi, 2012) particularly during challenging sociocultural transitions. ImS employees employed this strategy when faced with serious doubts about their own skills or interest in the job. This use of creative job crafting strategies not only highlights ImS employees' ability to self-reflect, but also showcases their resilience and determination.

In countering feelings of alienation, they developed fictive kinships within the workplace. We posit that fictive kinships, although similar in nature to the collegial relationships seen in urban IT-BPO workplaces (e.g., D'Mello \& Eriksen, 2010), are qualitatively different. Whilst we haven't quantified and compared the intensity of social bonds among ImS employees with those of urban IT-BPO employees, it was particularly noticeable in our fieldwork that the social cohesion among employees was markedly intense. This could be one of the reasons why ImS companies have such low employee attrition rates - around 5\% p.a. as opposed to an industry average of $40 \%$ p.a. (NASSCOM, 2014). Whilst extant research suggests that collegial support for newcomers may last up to 90 days on average (KammeyerMueller et al., 2013), our study suggest that social support extended to employees in ImS workplaces last much longer. There are two ways of explaining the special need for fictive kinships in rural ImS settings. In contrast to an urban IT-BPO setting, ImS employees can never escape the intense scrutiny, almost bordering on intrusive surveillance, of the local community. An ImS center and its immediate environment can be emotionally-charged places, where harsh judgements are often passed on the activities and moral character of ImS employees. While such situations can be interpreted in somewhat romantic terms as illustrations of the local communities' fight against the onslaught of globalization, in practice, they put ImS employees under tremendous psychological pressure. Fictive kinships can thus be understood as a strategy that helps ImS employees come together, share experiences and shield themselves against dogmatic societal strictures. The other explanation for fictive 
kinships is to view them as a cultural manifestation of the more collectivistic and less individualistic way of living common to rural settings.

\section{Developmental impacts of managing sociocultural transitions}

Despite the numerous challenges, sociocultural transitions also functioned as occasions for development during which ImpactHub employees learnt new skills and developed new capabilities to navigate unfamiliar situations. Figure 4 pictorially summarizes the process of realizing developmental impacts through sociocultural transitions. As our analysis revealed, transitions are triggered when ImS employees encounter a mismatch between the cultural worlds of their local community and the cultural settings of the workplace (Figure 4). For instance, in our case ImpactHub employees encountered workplace practices (e.g., working and socializing with the other gender) that contradicted the practices deemed legitimate in the community.

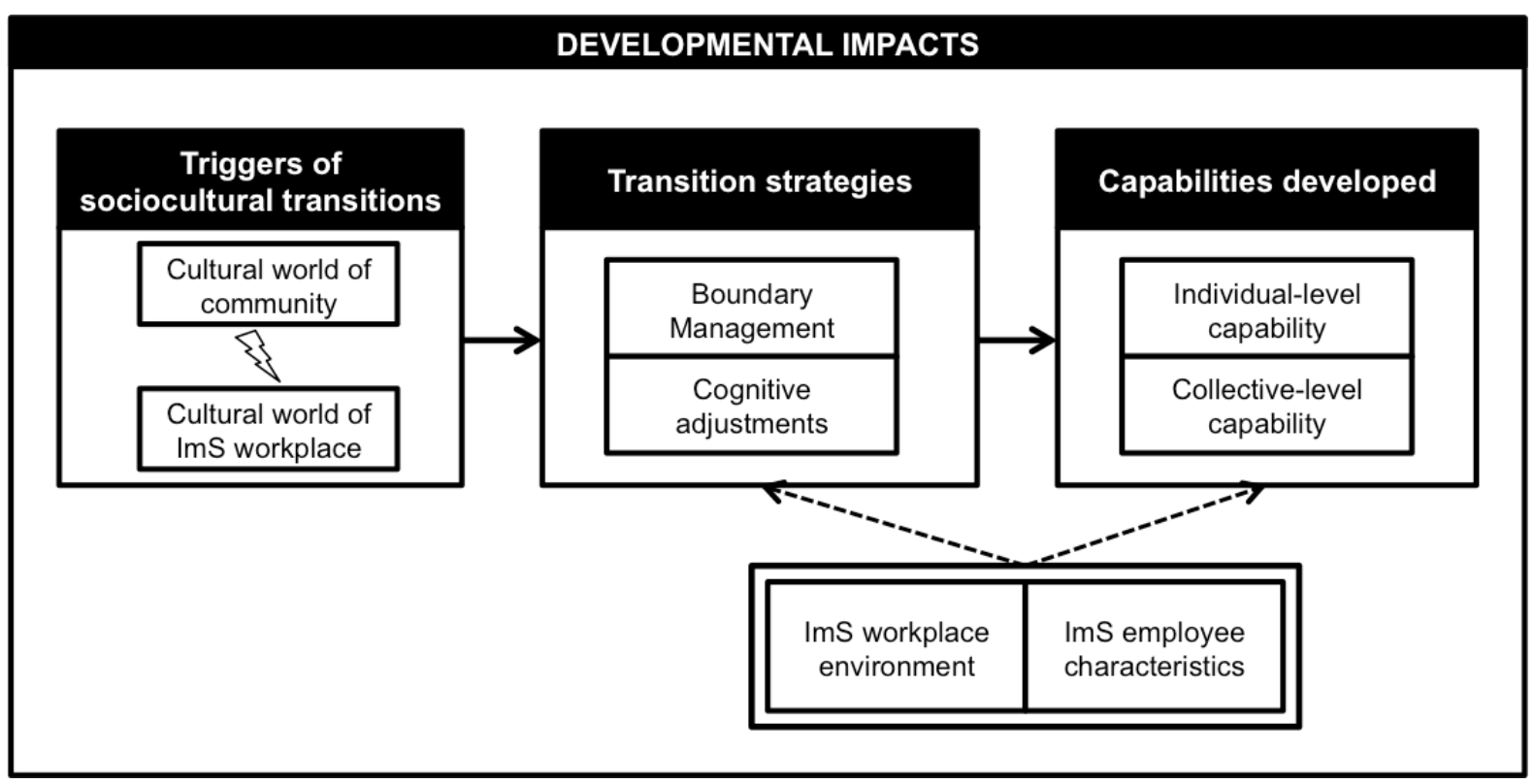

Figure 4. Developmental impacts of sociocultural transitions

Similarly, they faced conflicts while enacting newly acquired workplace practices in their community life. They responded with two broad categories of strategies: the management of boundaries between the community and ImpactHub, and the use of cognitive adjustments in the workplace (Figure 4). Periods of transitioning also function as occasions for individual and collective development (Zittoun et al., 2002). ImpactHub employees learnt new skills (e.g., use of ICTs, 
professional communication) and behaviors (e.g., socializing with the other gender), and developed several key capabilities at the individual and collective level (Figure 4).

We would argue that there are two distinct dimensions of positive developmental impacts in the ImpactHub story. First, the economic angle: A modest number of young people in an economically struggling community are now productively and gainfully employed. They have a degree of financial independence and access to much needed discretionary income. Rising household incomes and discretionary spending of ImS employees has also given a boost to the community's economy. The presence of ImpactHub and its employees has created local demand for goods and services that were earlier absent. In other words, positive trickle downeconomic effects are clearly visible. For instance, a local shopkeeper commented happily that he had opened a second store in the locality to cater to the rising demand for his goods. It is, however, important to acknowledge that these positive economic impacts are not immune to the power of market forces and wider political developments. A major concern for many ImS ventures is that they may not be able to sustain and scale, given the rapid proliferation of software automation and aggresive protectionist tendencies amongst the political establishment in North America and Europe.

A second dimension of developmental impacts is ImS's empowering effects on situated individuals. Many ImpactHub employees explained that ImS had given them dignity and respect. They were proud of their work at ImpactHub and generally felt more confident to face life. They developed a range of capabilities, which improved their life chances, gave them choices and helped them conduct their life in ways they considered meaningful. We would suggest that individual-level and collective-level capabilities of the kind we saw at ImpactHub and the feeling of psychological well-being they engender within communities is a crucial element of development. Not entirely couched in the language of economics, this perspective takes us closer to the "capabilities approach" developed by Sen (1999) and other scholars in the developmental studies field. In this view, "development" is conceptualized as the expansion of an individual's capability and by contrast, "poverty" is seen as capability deprivation (Sen, 1999). Theoretically at least, it is not 
difficult to connect the empowerment dimension to the economic aspects of development. As Nussbaum (2011) has observed, once an individual "is able to be and to do" his or her choosing, economic development invariably follows. In this sense, "development" could include both hard economic metrics as well as trickier to quantify outcomes related to self-confidence, social skills and psychological health.

It is, of course, simplistic to claim that the capabilities of each and every ImS employee gets developed and expanded during employment. Invariably, impact is a function, not only of the opportunities provided by the ImS workplace, but also of the inherent individual characteristics of ImS employees, such as cognitive skills and willingness to learn. Despite the best efforts of ImS companies there are bound to be some variations in individual experiences of transitions and impacts. With the ImS model, there is therefore a need to distinguish between the notion of equal opportunities and the notion of equal outcomes. We would argue that ImS belongs to a class of digital economy social businesses that generate equal opportunities and not necessarily equal outcomes for underprivileged communities. Whether the ImS model ought to explicitly focus on ensuring equal outcomes and whether such an option is even feasible are of course interesting questions, but they are likely to take us away from the practical realities of ImS companies into the world of ideologies.

A further note of caution on the "impact" potential of ImS companies is appropriate at this juncture. While our study has largely reported positive outcomes of the ImS model, there can be unintended negative consequences as well. For instance, ImS senior managers may not always get the pace of their employee training programs right. New ideas, worldviews and digital technologies can be introduced too quickly into the everyday work life of employees, who may find it stressful and hard to cope mentally. Such occasions may further amplify rather than ameliorate the initial sense of discomfort that employees experience when they enter the ImS workplace. Moreover, as our findings revealed, digitally-enabled models such as ImS can brew a sense of suspicion around the nature of work that transpires within the workplace. The local community wasn't entirely sure about "what's going on" within the confines of ImpactHub workplaces, sometimes leading to rumour mongering. This situation can be largely attributed to the intangibleness of digital 
work and the artefacts produced in the process ${ }^{5}$. As the community obtained more information (even if such information was slightly abstract) about the nature of digital production, the sense of suspicion was invariably replaced with a sense of pride that their son or daughter was working for a "computer" company in a white collar job.

ImpactHub is one illustration of the digital economy and its impacts in an emerging market context. It showcases the potential of digitally-enabled sourcing models to generate employment opportunities in regions that several (say) manufacturing enterprises shy away from investing in due to institutional voids and infrastructural lacunae. With relatively low capital commitments, digitally-enabled ImS models enable entrepreneurs to bring jobs right to the doorstep of disadvantaged communities. It helps local communities, especially women, to take up productive digital work. In this sense, the developmental impacts of the digital economy of ImS appear to be both substantive and inclusive.

\section{Practical implications for ImS companies}

From an ImS company's standpoint, our study highlights the importance of paying close attention to the transitions undertaken by its employees. Recent research suggests that both organizations and its employees are better off when employees' authentic self-expression is encouraged in the workplace (Cable et al., 2013). Promoting "self-initiated" socialization (for e.g., experimentation with provisional selves) is one way in which ImS companies can encourage authentic self-expressions amongst its employees. Knowledge of such strategies can help organizations facilitate transition and improve employee satisfaction and well-being. For instance, organizations could encourage mentoring relationships among coworkers and support fictive kinship groups within the workplace.

ImS employees who carry new cultural material back to their communities may enact hybrid cultures within the community. As some of these practices and beliefs may be antithetical to the views of the community, the company's relationships with the local community may be affected. Managing relationships with the local community can be crucial for the sustainability of ImS companies (Sinkovics et al., 2014; Sandeep and Ravishankar, 2015). Therefore, a deeper understanding of

\footnotetext{
5 We thank anonymous reviewer 2 for helping us develop this line of thought.
} 
how employees make sociocultural transitions may forewarn senior managers of the potential backlash from the local community and help them take some pre-emptive steps.

The study also highlights the developmental impacts of managing transitions. We urge ImS practitioners to document and report developmental impacts since it is one of their core missions. A number of ImS companies (including ImpactHub) have attracted investments from "social venture" capital funds and "impact investors". These funds invest in organizations that hold the promise of creating both social and economic returns. However, as Foose \& Folan (2016) note, impact investors rarely outline how social impact should be documented and reported, leaving much of it to the imagination of the organization. ImS companies, apart from a handful rarely document "impacts", and when they do the focus is invariably only on "economic impacts" (e.g., rise in income levels). Foose \& Folan (2016) warn impact investors against treading the same path as many microfinance institutions did a decade ago, whereby social performance had come to be almost taken for granted. Understanding and documenting social impact gives ImS companies a better sense of the changes being effected in its employees and local community. Moreover, having such a documentation practice can send out right messages (about their social mission) to investors who are in a position to control the fortunes of ImS companies.

Finally, the findings of our study should reassure entrepreneurs and companies considering an ImS strategy. Despite the obvious contextual differences, the transition strategies adopted by our informants (e.g., boundary management) are not entirely dissimilar to what one might expect to see in an urban-educated IT-BPO employee. Rural locations in India and their employee base, in this sense, are normal and familiar rather than exotic and strange. Coupled with the obvious cost benefits for operating outsourcing ventures that such locations offer, the insights from our findings can help de-mythologize rural settings and inspire entrepreneurs to seriously consider ImS as a viable business strategy. As our study demonstrated, an ImS strategy can provide access to a highly committed and culturally resourceful workforce. 


\section{CONCLUDING REMARKS}

In recent years the ImS business model has generated attention, especially within the IS scholarly community, for its ability to create social impact through digitally-enabled work. This paper contributes to this small but growing stream of literature by demonstrating how employees manage the everyday sociocultural challenges of transition in the growing digital economy of ImS. It explains how ImS employees develop a range of strategies to overcome the challenges in the workplace and to manage diverse cultural expectations within the community. The paper also provides insights into the crucial individual-level and collective-level capabilities developed in the transition process.

Our qualitative study has several limitations. First, it hasn't fully taken into account ImpactHub's role in facilitating transitions. Future research on ImS companies needs to explore the influence of formal organizationally-driven socialization efforts on the sociocultural transition of ImS employees. Second, our case study focused on ImS employees in one company in rural North India. Therefore generalizations from the case apply largely to similar contexts. The transition experience of ImS employees in other settings could be different and is thus a fruitful line of further enquiry. Also, future research could undertake a precise objective mapping of the different transition strategies to the development of different capabilities. Third, in our analysis of transitions and developmental impacts, we did not focus particularly on the gender dimension. Further research is required to compare and contrast sociocultural transition strategies between male and female ImS employees. Lastly, our study has largely reported positive impacts of the ImS model. We are by no means suggesting that there are no negative aspects of the ImS model. The assessment of developmental impacts is a complex, and often ideologically fraught exercise, which can take many years. Therefore, to fully understand the long-term developmental impacts (both positive and negative) of the ImS model, longitudinal studies comprising research teams from multiple disciplines are needed.

\section{REFERENCES}


Ashford, S. J. \& Black, J. S. (1996) Proactivity during organizational entry: The role of desire for control. Journal of Applied Psychology, 81,199-214.

Bailur, S. (2007) The complexities of community participation in ICT for development projects: The case of 'Our Voices'. Proceedings of the 9th International Conference on Social Implications of Computers in Developing Countries, São Paulo, Brazil.

Beach, K.D. (1999) Consequential transitions: A sociocultural expedition beyond transfer in education. Review of Research in Education, 24, 101-139.

Berg, J. M., Wrzesniewski, A. \& Dutton, J. E. (2010) Perceiving and responding to challenges in job crafting at different ranks: when proactivity requires adaptivity. Journal of Organizational Behavior, 31, 158-86.

Berry, J. W. (2003) Conceptual approaches to acculturation. In: Acculturation: Advances in theory, measurement and applied research, K. M. Chun, P. B. Organista, \& G. Marin (eds.), pp.17-36. American Psychological Association, Washington, DC.

Broadband Commission (2014) The State of Broadband 2014: broadband for all. [pdf] Available at: http://www.broadbandcommission.org/Documents/reports/bbannualreport2014.pdf [Accessed 3 January 2015]

Cable, D.M., Gino, F. \& Staats, B. (2013) Breaking Them in or Eliciting Their Best? Reframing Socialization around Newcomers' Authentic Self-expression. Administrative Science Quarterly, 58,1-36.

Carmel, E., Lacity, M. \& Doty, A. (2013) The Impact of Impact Sourcing: Framing a Research Agenda. $4^{\text {th }}$ International Conference on the Outsourcing of Information Services, Mannheim, Germany.

Carsten, J. (1995) The substance of kinship and the heat of the hearth: feeding, personhood, and relatedness among Malays in Pulau Langkawi. American Ethnologist, 22, 223-241.

Comim, F. \& Carey, F. (2001) Social Capital and the Capability Approach: are Putnam and Sen incompatible bedfellows? In the proceedings of EAEPE Conference, 8-11 November, Siena, Italy.

Cooper-Thomas, H., Anderson, N. \& Cash, M. (2011) Investigating organizational socialization: a fresh look at newcomer adjustment strategies. Personnel Review, 41, 41-55. 
D’Mello, M., \& Eriksen T.H. (2010) Software, sports day and Sheera: Culture and identity processes within a global software organization in India. Information and Organization, 20, 81-110.

Everest Group (2014) The case for impact sourcing. [pdf] Available at: $\quad$ http://www.everestgrp.com/wp-content/uploads/2014/09/RF-The-Case-forImpact-Sourcing-Final-approved vf.pdf [Accessed 20 March 2014]

Feldman, D.C. \& Brett, J.M. (1983) Coping with new jobs: a comparative study of new hires and job changers. Academy of Management Journal, 26, 258-72.

Foose, L., \& Folan, A. (2016) What Impact Investors Can Learn from the Microfinance Industry. [WWW Document] Available at: http://ssir.org/articles/entry/what impact investors can learn from the microf inance industry\#sthash.veb6CvY9.dpuf [Accessed 16 March 2016].

Goffman, E. (1959) The Presentation of Self in Everyday Life. Doubleday, New York. Gorgorió, N., Planas, N., \& Vilella, X. (2002) Immigrant children learning mathematics in mainstream schools. In: Transitions between contexts of mathematical practice Abreu, G. de, Bishop, A., \& Presmeg, N.C. (eds.), pp.23-52. Kluwer Academic Publishers, Guile.

Gupta, S. (2014) Modeling district level economic disparities across Uttarakhand, India. ÎOSR Journal of Humanities and Social Science, 19, 84-90.

Heeks, R. (2013) Information Technology Impact Sourcing. Communications of the ACM, 56, 22-25.

Heeks, R. \& Arun, S. (2010) Social outsourcing as a development tool: the impact of outsourcing IT services to women's social enterprises in Kerala. Journal of International Development, 22, 441-454.

Ibarra, H. (1999) Provisional selves: Experimenting with image and identity in professional adaptation. Administrative Science Quarterly, 44, 764-791.

Jones, G.R. (1986) Socialization tactics, self-efficacy, and newcomers' adjustments to organizations. Academy of Management Journal, 29, 262-79.

Kammeyer-Mueller, J., Wanberg, C.R., Rubenstein, A. \& Song, Z. (2013) Support, undermining, and newcomer socialization: Fitting in during the first 90 days. Academy of Management Journal, 56, 1104-1124.

Kende, M. (2015) The shrinking digital divide. [WWW] Available at: http://techcrunch.com/2015/07/12/the-shrinking-digital-divide/ [Accessed 30 July 
2015].

Klein, H. K. \& Myers, M.D. (1999) A Set of Principles for Conducting and Evaluating Interpretive Field Studies in Information Systems. MIS Quarterly, Special Issue on Intensive Research, 23, 67-93.

Kramer, M.W. (1993) Communication after job transfers - social-exchange processes in learning new roles. Human Communication Research, 20, 147-174.

Kubzansky, M., Cooper, A. \& Barbary, V. (2011) Beyond Aid. Monitor Group, Boston. Lacity, M., Carmel, E. \& Rottman, J.W (2011) Rural Outsourcing: Delivering ITO and BPO Services from Remote Domestic Locations. IEEE Computer, 44, 55-62.

Lacity, M., Rottman, J.W., \& Carmel, E. (2014) Impact Sourcing: Employing Prison Inmates to Perform Digitally-enabled Business Services. Communications of the Association for Information Systems, 34, 913-932.

LaFromboise, T., Coleman, H. L. K., \& Gerton, J. (1993) Psychological impact of biculturalism: Evidence and theory. Psychological Bulletin, 114, 395-412.

Lamont, M. \& Molnár, V. (2002) The Study of Boundaries in the Social Sciences. Annual Review of Sociology, 28, 167-195.

Lawrence, T. B., Suddaby, R. \& Leca, B. (2009) Introduction: theorizing and studying institutional work. In T.B. Lawrence, R. Suddaby, \& B. Leca (Eds.), Institutional work: Actors and agency in institutional studies of organizations (pp. 1-27). Cambridge, UK: Cambridge University Press.

Liu, S., Wang, M., Bamberger, P., Shi, J. \& Bacharach, S. B. (2015) The dark side of socialization: A longitudinal investigation of newcomer alcohol use. Academy of Management Journal, 58, 334-355.

Locke, K (2001) Grounded Theory in Management Research, Sage Publications, London, Thousand Oaks.

Lu, C.-Q, Wang, H.-J, Lu, J.-J, Du, D.-Y \& Bakker, A.B (2014) Does work engagement increase person-job fit? The role of job crafting and job insecurity. Journal of Vocational Behavior, 84, 142-152.

Madon, S. \& Sharanappa, S. (2013) Social IT sourcing and development: Theorizing the linkage. Information Systems Journal, 23, 381-399.

Malik, F., Nicholson, B. \& Morgan, S. (2013) Assessing the social development potential of impact sourcing. Proceedings of the $6^{\text {th }}$ Annual Conference SIG GlobDev, Milan, Italy. 
Mamgain, R.P. (2016) Diversification in Rural Livelihood in Uttarakhand. In: Indian Agriculture: Performance, growth and challenges, ^ P. Kumar and S.Mohanakumar (eds.), New York, Routledge.

Mamgain, R.P. \& Reddy, D.N. (2015) Outmigration from hill region of uttarakhand: Magnitude, Challenges and Policy Options. [pdf] Available at: http://www.nird.org.in/SRSankaranChair/LEICERUC17.pdf [Accessed 12 February 2016].

Matarelli, E. \& Tagliaventi, M.E. (2012) How Offshore Professionals' Job Dissatisfaction Can Promote Further Offshoring: Organizational Outcomes of Job Crafting. Journal of Management Studies, available online, doi: 10.1111/j.14676486.2012.01088.x.

Mayasandra, R., Pan, S.L, \& Myers, M.D. (2006). Viewing information technology outsourcing organisations through a postcolonial lens. In: Social Inclusion, Societal and Organisational Implications for Information Systems, E. Trauth, D. Howcroft, T. Butler, B. Fitzgerald, and J. De Gross (eds.), pp.381-396, Berlin, Springer.

Molinsky, A.L. (2013) The psychological processes of cultural retooling. Academy of Management Journal, 56, 683-710.

NASSCOM (2014) Next generation outsourcing: opportunities through Impact Sourcing. [pdf] Available at : https://www.nasscomfoundation.org/images/resources/Next Generation Outs ourcing Impact Sourcing.pdf [Accessed 21 August 2015].

NSDC (2013) Executive summary for the State of Uttaranchal. [pdf] Available at: http://www.nsdcindia.org/sites/default/files/files/uttrakhand-executivesummary.pdf [Accessed 21 December 2016].

Nussbaum, M.C. (2011) Creating capabilities: The human development approach. Harvard University Press, Cambridge, MA.

Ogbu, J. U. (1991) Immigrant and involuntary minorities in comparative perspective. In: Minority status and schooling: A comparative study of immigrant and involuntary minorities, M. A.Gibson \& J. U. Ogbu (eds.), pp. 3-33, New York, Garland Press. 
Pratt, M.G, Rockmann, K.W. \& Kauffmann, J.B. (2006) Constructing professional identity: the role of work and identity learning cycles in the customization of identity among medical residents. Academy of Management Journal, 49, 235-262.

Raghuram, S. (2013) Identities on call: Impact of impression management on Indian call center agents. Human Relations, 66, 1471-1496.

Ravishankar, M.N., Cohen, L. \& El-Sawad, A. (2010) Examining resistance, accommodation and the pursuit of aspiration in the Indian IT-BPO space: reflections on two case studies. Industrial Relations Journal, 41, 154-167.

Sandeep, M.S. \& Ravishankar, M.N. (2015) Social innovations in outsourcing: An empirical investigation of impact sourcing companies in India. The Journal of Strategic Information Systems, 24, 270-288.

Sandeep, M.S. \& Ravishankar, M.N. (2016) Impact sourcing ventures and local communities: A frame alignment perspective. Information Systems Journal, 26, 127-155.

Sen, A. (1999) Development as Freedom. Oxford University Press, New York.

Sinkovics, N., Sinkovics, R.R. \& Yamin, M. (2014) The role of social value creation in business model formulation at the bottom of the pyramid - implications for MNEs? International Business Review, 23, 692-707.

Strauss, A. \& Corbin, J. (1998) Basics of Qualitative Research: Techniques and Procedures for Developing Grounded Theory, 2nd edn. Sage, Thousand Oaks, CA.

Tierney, W.G. \& Venegas, K.M. (2006) Fictive Kin and Social Capital: The Role of Peer Groups in Applying and Paying for College. American Behavioural Scientist, 49, 1687-1702.

Upadhya, C. \& Vasavi, A.R. (2006) Work, culture, and sociality in the Indian IT industry: a sociological study. National Institute of Advanced Studies, Indian Institute of Science Campus, Bangalore.

Van Maanen, J. \& Schein, E.G. (1979) Toward a theory of organizational socialization. In: Research in Organizational Behavior, B. M. Staw and L. L. Cummings (eds.), pp. 209-264. JAI Press, Greenwich, CT.

Venkatesh, S. (2015) Why this abandoned village is a threat to Uttarakhand. [WWW Document] Available at: http://www.downtoearth.org.in/coverage/why-thisabandoned-village-is-a-threat-to-uttarakhand-52154 [Accesssed 13 January 2016]. 
Walsham, G. (1995) The emergence of interpretivism in IS research. Information Systems Research, 4, 376-394.

Walsham, G. (2006) Doing interpretive research. European Journal of Information Systems, 15, 320-330.

William Davidson Institute (2013) Impact Sourcing - Assessing the Opportunity for Building a Thriving Industry [Online]. Rockefeller Foundation. Available: www.rockefellerfoundation.org/app/uploads/Assessing-the-Opportunity-for-

Building-a-Thriving-Industry.pdf [Accessed 23 December 2016].

Wrzesniewski, A., Berg, J.M. \& Dutton, E. (2010) Managing Yourself: Turn the Job You Have into the Job You Want. [WWW Document] Available at: https://hbr.org/2010/06/managing-yourself-turn-the-job-you-have-into-the-jobyou-want. [Accessed 10 June 2015].

Wrzesniewski, A. \& Dutton, J. E. (2001) Crafting a job: Revisioning employees as active crafters of their work. Academy of Management Review, 26, 179-201.

Zittoun, T., Duveen, G., Gillespie, A., Ivinson, G. \& Psaltis, C. (2003) The use of symbolic resources in developmental transitions. Culture \& Psychology, 9, 415448. 